\title{
Kinematic Analysis on the Forehand Stroke of ATP Tennis Player Karen Khachanov
}

\author{
Chuanjia $\mathrm{Du}^{1, *}$, Jihe Zhou ${ }^{2}$, and Shuai Wang ${ }^{1}$ \\ ${ }^{1}$ Chengdu Sport Institute, 610041, Chengdu, Sichuan, China \\ ${ }^{2}$ Chengdu Sport Institute, Sports Medicine Department, 610041, Chengdu, Sichuan, China
}

\begin{abstract}
By using the three-dimensional video analysis method to kinematic analyze the forehand stroke technique of the ATP professional tennis player, Karen Khachanov. Exploring the action mode and characteristics from him to provide a reference for all tennis learners to improve their forehand stroke. The results show that: (1) At the end of the preparation, Karen Khachanov's center of gravity was lower, and his body control was steady; (2) After the follow through, each joint of Karen Khachanov's racquet arm were stretched, so the swing radius is larger. His right leg was like a support point for the next stage---drive leg and rotate hip; (3) At the swing stage, the move of his driving leg and rotating hip was full, so the whole hitting action match the principle whipping technique movement. (4) The "wiper" style follow through was natural, coordinated, and smooth. After hitting the ball, his body of control was steady, the shoulder movement was obvious, and the hitting was fast and powerful. Conclusion: The forehand stroke of Karen Khachanov was a high quality hitting action, and it's worthy of tennis players to learn from.
\end{abstract}

\section{Introduction}

Tennis is a complex sport. The complexity is not only reflected in the game and the process of competitors' game, but more reflected in the technical action sequence structure of the correctness and stability. In all techniques, forehand stroke is the most frequently used technique with more than $70 \%$ usage[3]. Therefore, the study of forehand stroke is particularly important. This

\section{Object and method}

\subsection{Object}

Russian tennis star, Karen khachanov (refer to Table 1 for personal information ). In July 2013, he won the under 18 European champion, and won the single match paper used three-dimensional video analysis method to analyze the forehand stroke of the ATP professional tennis player, Karen Khachanov. Collecting kinematic data, carry on the kinematics analysis, and explore the forehand movement mode, and the four major ways of the study to provide reference to learn forehand stroke theory. champion in the International ATP250 Chengdu Open 2016.

Table 1. Basic information of Karen Khachanov

\begin{tabular}{ccccc}
\hline Birth & $\begin{array}{c}\text { Height } \\
(\mathrm{m})\end{array}$ & $\begin{array}{c}\text { Weigh } \\
(\mathrm{kg})\end{array}$ & $\begin{array}{c}\text { Dominate } \\
\text { hand }\end{array}$ & $\begin{array}{c}\text { Highest } \\
\text { ranking }\end{array}$ \\
\hline $1996 / 5 / 21$ & 1.98 & 88 & Right & 48 \\
\hline
\end{tabular}

\subsection{Method}

\footnotetext{
* Corresponding author: 549828421@qq.com
} 
Three-dimensional video analysis: Two JVC-GCPX10AC high-speed cameras (50fps) were used in the International ATP250 Chengdu Open 2016 to shoot Karen Khachanov's technique movements. The axis of the two cameras is about $50^{\circ}$ (the position of cameras is showed in Fig. 1). The selected video was the last forehand stroke in the 2 nd point of the first games first set. Inputting the selected video part in the 3-D Signal TEC V2.0C analysis system. Choosing the Dempster manikin (with 16 links, 21 joint parameters). In the meantime, adding the racket session for the study. Using the step by step analysis method and the low-pass filter to smoothing process to point data and get the results.

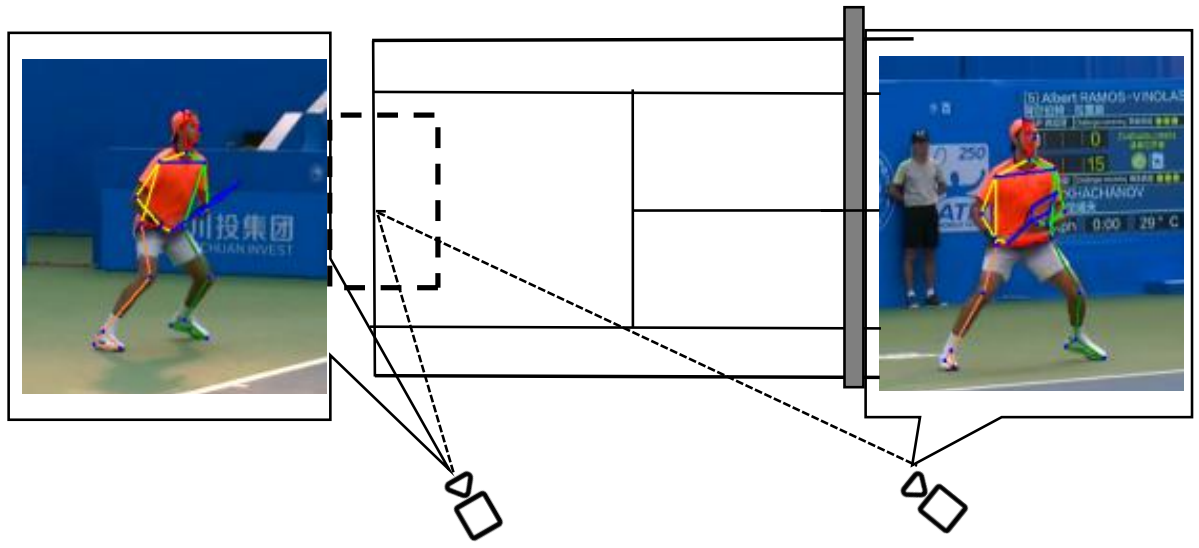

Fig.1. Diagram of cameras position

\section{Results}

\subsection{Definition of moments, division of stages, selection and definition of joint}

\section{Definition of moments}

$\mathrm{T}_{1}$ The moment of the end of preparation: The moment that feet are split step and backswing.

$\mathrm{T}_{2}$ The moment of backswing: The moment that the racket hand behinds the farthest.

$\mathrm{T}_{3}$ The moment of touching the ball: The moment that the racket is going to touch the ball.

$\mathrm{T}_{4}$ The moment of end of follow through: The moment that the angle is the maximum between shoulder and hip

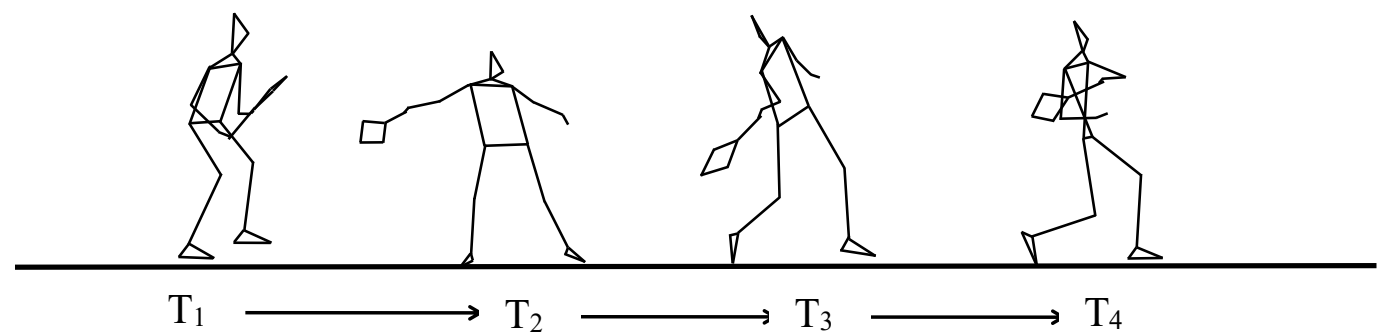

Fig. 1. division of stages

Note: $T_{1}$ : The moment of the end of preparation, $T_{2}$ : The moment of backswing, $\mathrm{T}_{3}$ : The moment of touching the ball, $\mathrm{T}_{4}$ : The moment of end of follow through. $\mathrm{T}_{1-2}$ : Backswing stage, $\mathrm{T}_{2-3}$ : Swing stage, $\mathrm{T}_{3-4}$ : Follow through stage.

Selection and definition of joints angle

\footnotetext{
* Corresponding author: 549828421@qqq.com
} 


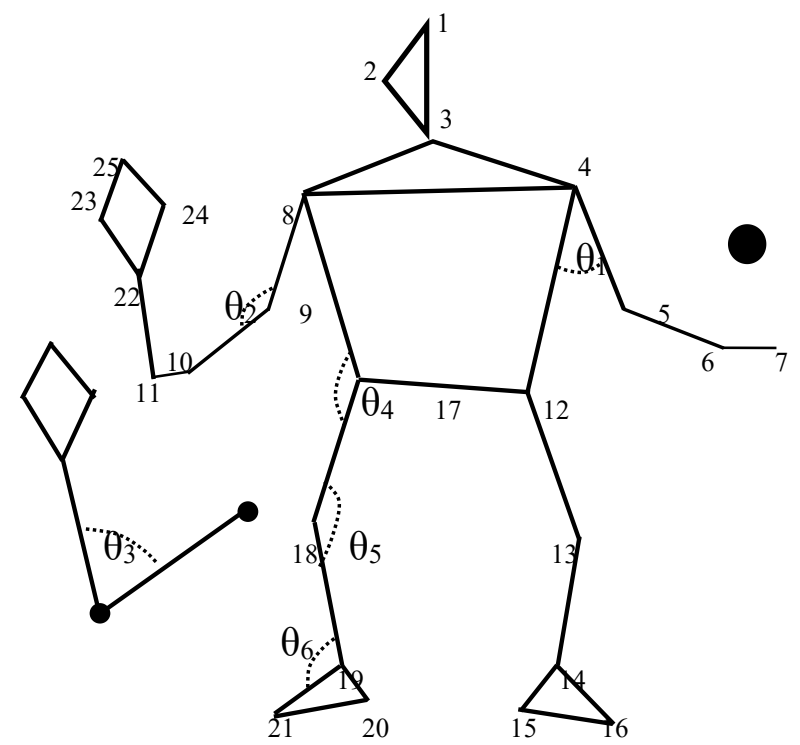

Fig. 2. Manikin and parts of parameters

Note: $\theta_{1}$. Shoulder joint angle, $\theta_{2}$. Elbow joint angle, $\theta_{3}$. Racket-forearm angle,

$\theta_{4}$. Hip joint angle, $\theta_{5}$.Knee joint angle, $\theta_{6}$.Ankle joint angle

Shoulder angle: The angle between shoulder and upper arm.

Elbow joint angle: The angle between upper arm and forearm.

Racket-forearm angle: The angle between the forearm and racket.

Hip joint angle: The angle between hip and thigh.

Knee joint angle: The angle between thigh and crus.

Ankle joint angle: The angle between crus and ankle.

\subsection{Analysis of the backswing stage}

The backswing stage means the process that the player is prepared and backswing. Under the non-forced circumstance, the player would have more time to adjust the body positon, and to determine the hit line to improve the quality of return. Before adjusting the position, normally player have the split step movement to adjust the dance and backswing.

Table 2. Parameters about the end of preparation

\begin{tabular}{cccccccccc}
\hline $\begin{array}{c}\text { Center of } \\
\text { gravity } \\
(\mathrm{m})\end{array}$ & $\begin{array}{c}\text { Right } \\
\text { shoulder } \\
\left({ }^{\circ}\right)\end{array}$ & $\begin{array}{c}\text { Right } \\
\text { elbow } \\
\left({ }^{\circ}\right)\end{array}$ & $\begin{array}{c}\text { Racket } \\
\text { forearm } \\
\left({ }^{\circ}\right)\end{array}$ & \multicolumn{2}{c}{ Hips $\left({ }^{\circ}\right)$} & \multicolumn{2}{c}{ Knees $\left(^{\circ}\right)$} & \multicolumn{2}{c}{ Ankles $\left(^{\circ}\right)$} \\
\hline 0.92 & 30.3 & 94.4 & 106.3 & 123.6 & 121.6 & 125.3 & 108.9 & 98.5 & 101.6 \\
\hline
\end{tabular}

At the end of preparation, the height of Karen Khachanov's center of gravity was $0.92 \mathrm{~m}$, compared to his normal anatomy of the height, $1.20 \mathrm{~m}$, his height was lowered $0.28 \mathrm{~m}$. The bent of each lower limb joint showed the center of graving was down, at that time, the angles of Karen Khachanov's left and right hip joint angle were $123.6^{\circ}, 121.6^{\circ}$. The left and right knee joint angles were $125.3^{\circ}, 108.9^{\circ}$, and the left and right ankle joint angles were $98.5^{\circ}, 101.6^{\circ}$. The hip, knees and angles of Karen Khachanov were bent, body control was steady, and compared to his left knee joint angle, the bent angle of his left knee joint was larger, according to the data. All these indicate that at the time of after preparation, Karen Khachanov already knew the coming ball from his competitor would point to his own forehand position. Therefore, his body adjusted in a shore time, and stayed in a relative lower center of gravity to finish all following movements better. His right shoulder joint angle and elbow joint angle were $30.3^{\circ}, 124.4^{\circ}$, and the racket-forearm angle was $106.3^{\circ}$, which means Karen Khachanov's racket hand was naturally bent at that time.

After players forecast the position of the coming ball, they will move into the next stage, which is the backswing stage. Backswing stage is the reverse movement of forehand stroke. The purpose of backswing is to enlarge the radius and range of the movement. So the racket hand that is associated with muscle elongation and elasticity will help finish next stage movements. The kinematic parameters are important factors at the moment of the end of backswing stage that are used to determine the effect of the player's pre-elongated elasticity.

Table 3. Parameters about the end of backswing

\begin{tabular}{cccccccccc}
\hline $\begin{array}{c}\text { Center of } \\
\text { gravity } \\
(\mathrm{m})\end{array}$ & $\begin{array}{c}\text { Right } \\
\text { shoulder } \\
\left({ }^{\circ}\right)\end{array}$ & $\begin{array}{c}\text { Right } \\
\text { elbow } \\
\left({ }^{\circ}\right)\end{array}$ & $\begin{array}{c}\text { Racket } \\
\text { forearm } \\
\left({ }^{\circ}\right)\end{array}$ & $\begin{array}{c}\text { Hips }\left(^{\circ}\right) \\
\text { Left }\end{array}$ & Right & Knees $\left(^{\circ}\right)$ & \multicolumn{2}{c}{ Ankles $\left(^{\circ}\right)$} \\
\hline 0.87 & 79.4 & 149.5 & 136.8 & 144.8 & 131.5 & 132.6 & 112.1 & 88.7 & 81.5 \\
\hline
\end{tabular}


At the end of backswing, the right shoulder joint angle and right elbow joint angle of Karen Khachanov were $79.4^{\circ}, 149.5^{\circ}$, and the racket-forearm angle was $136.8^{\circ}$. Related research pointed out ${ }^{[1]}$ : The angle of right shoulder and elbow shows the player's hitting-arm stretch state at the end of backswing, compared to the trunk; At this moment, the right shoulder and the right elbow joint's angle of Andy·Murray were $46.5^{\circ}, 136.53$ ○. That means at this moment, Karen Khachanov's hitting-arm of the joints stretched fully and lead to the larger swing radius. At the end of backswing, Karen Khachanov chose the semi-open stance, and his left and right hip joint angles were $144.8^{\circ}, 131.5^{\circ}$; the left and right knee joint angles were $132.6^{\circ}, 112.1^{\circ}$, and the left and right ankle joint angles were $88.7^{\circ}, 81.5^{\circ}$, the set of data shows that Karen Khachanov used his right leg as the main supporting function at this moment. The height of Karen Khachanov's center of gravity was $0.87 \mathrm{~m}$, compared with the after preparation time's center of

\subsection{Analysis of the swing stage}

The swing stage refers to the process from the backswing to the moment to contact the ball. This is the functional action in the forehand stroke, and it is the core gravity, which was $0.92 \mathrm{~m}$; the center of gravity down value was $0.05 \mathrm{~m}$. The main reason was Karen Khachanov deliberately to keep the center of gravity focus on the right leg. A literature shows ${ }^{[2]}$ that the strength of forehand stroke comes from the ground, the right knee fast forceful extension to promote the formation of angular momentum, knee angular momentum deliver to the hip, shoulder, elbow, wrist and then get through racket head to form a complete power chain system.In the process, nevertheless, the premise of right knee fast forceful extension was that the center of gravity near to the right leg. The external performance of the center of gravity near to the right leg was that the right lower limb flexor than the left lower limb was more obvious. Therefore, through the kinematic parameters of the lower limbs show that Karen Khachanov's whole body center of gravity close to the right leg, which means established the advantageous condition for the next stage of hitting the ball.

action of the forehand technique. In this stage, the players need to push off ground to get a larger angular velocity quickly and adequately, driving the hitting-arm to finish the stroke.

Table 4. Parameters about the moment of contact the ball

\begin{tabular}{cccccccccc}
\hline $\begin{array}{c}\text { Center of } \\
\text { gravity } \\
(\mathrm{m})\end{array}$ & $\begin{array}{c}\text { Right } \\
\text { shoulder } \\
\left({ }^{\circ}\right)\end{array}$ & $\begin{array}{c}\text { Right } \\
\text { elbow } \\
\left({ }^{\circ}\right)\end{array}$ & $\begin{array}{c}\text { Racket } \\
\text { forearm } \\
\left({ }^{\circ}\right)\end{array}$ & $\begin{array}{c}\text { Hips } \\
\text { Left }\end{array}$ & Right & Knees $\left(^{\circ}\right)$ & \multicolumn{2}{c}{ Ankles $\left(^{\circ}\right)$} \\
Left & Right & Left & Right \\
\hline 0.94 & 62.3 & 107.1 & 105.4 & 157.8 & 166.8 & 165.0 & 154.6 & 124.2 & 115.0 \\
\hline
\end{tabular}

At the moment of touching the ball, if the starting point is too close to the body, there will happen to "squeeze" phenomenon. The most intuitive performance shows that the shoulder angle is too small, and if the starting point away from the normal position, the shoulder and elbow angles will be too large, the backswing stage established by the larger waving radius advantage will be affected.

At the moment of touching the ball, the height of Karen Khachanov's center of gravity was $0.94 \mathrm{~m}$, the right shoulder joint, right elbow joint and racket-forearm angle were $62.3^{\circ}, 107.1^{\circ}$ and $105.4^{\circ}$. Through these data and combined with the video record we can see that: in this stroke, Karen Khachanov's control of the starting point was appropriate, which was an important prerequisite for this stroke to complete the winning points. At the same time, the data show that Karen Khachanov's the left and right hip angle were $157.8^{\circ}$, $166.8^{\circ}$; the left and right knee angle were $165.0^{\circ}, 154.6$ $\circ$, the left and right ankle angle were $124.2^{\circ}, 115.0^{\circ}$. Karen Khachanov's two knees are still in the buckling state, the height of the center of gravity was still lower than the standing position; observed from the Y-X plane, the projection point of Karen Khachanov's center of gravity in the left foot horizontal position, which shows that Karen Khachanov has been a significant kick his leg and then rotated his hip adequately, and the action means the center of gravity were rapid transfer.

Table 5. Parameters about the swing stage $(\mathrm{m} / \mathrm{s})$

\begin{tabular}{ccccccc}
\hline $\begin{array}{c}\text { Center of } \\
\text { gravity }\end{array}$ & $\begin{array}{c}\text { Right } \\
\text { knee }\end{array}$ & $\begin{array}{c}\text { Right } \\
\text { hip }\end{array}$ & $\begin{array}{c}\text { Right } \\
\text { shoulder }\end{array}$ & $\begin{array}{c}\text { Right } \\
\text { elbow }\end{array}$ & $\begin{array}{c}\text { Right } \\
\text { wrist }\end{array}$ & $\begin{array}{c}\text { Racket } \\
\text { head }\end{array}$ \\
\hline 0.86 & 1.32 & 1.47 & 2.68 & 5.46 & 11.21 & 22.61 \\
\hline
\end{tabular}

A good swing action must be consistent with the principle of whipping action, that is, the speed of the proximal to the link of distal increasing in turn. There are some differences technical principles between the tennis forehand whipping and the whipping of throwing items. For example, in the process of throwing javelin movement, the javelin, as a whole part is a parallel movement. But the forehand in swing stage, the racket as a whole part around the player's frontal axis will do rotational movement, and then make the racket head get more acceleration. In the swing stage, the racket- arm angle used to be as an important indicator to judge the effect of whipping action and increasing the speed of the racket.

\footnotetext{
* Corresponding author: 549828421@qq.com
} 


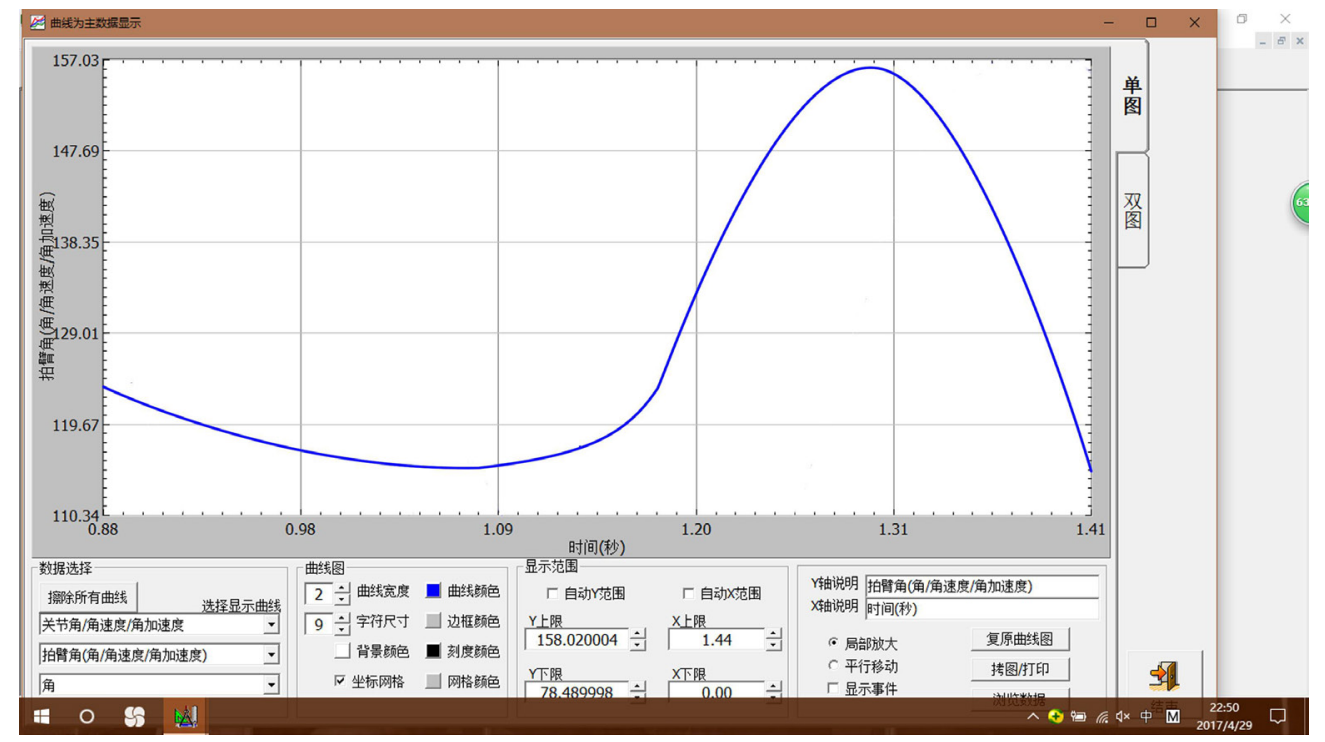

Fig. 2. Racket-forearm angle variation over time

We can see from Fig. 4, during the process of swing stage, the arm angle rapidly reduced to $106.7^{\circ}$, at the moment of touching the ball, the arm angle instantaneously increased to $123.4^{\circ}$. which means during the swing stage, Karen Khachanov's racketforearm angle first gradually reduced and instantaneous increased in the moment of contacted the ball, so to achieve the effect of speeding the head. Data shows that at the moment to touch the ball, Karen Khachanov's right knee speed was $1.32 \mathrm{~m} / \mathrm{s}$, the right hip speed was
$1.47 \mathrm{~m} / \mathrm{s}$, which also demonstrated that Karen Khachanov's kicked the hips and rotated his whole body significantly in the process of Swing stage. Furthermore, table 4 also showed: Karen Khachanov's right shoulder joint, right elbow joint, right wrist joint and racket head speed were $2.68 \mathrm{~m} / \mathrm{s}, 5.46 \mathrm{~m} / \mathrm{s}, 11.21 \mathrm{~m} / \mathrm{s}$ and $22.61 \mathrm{~m} /$ $\mathrm{s}$. From that, the proximal end of the link to the speed of the speed increases at the moment of touching the ball, the head speed was $22.61 \mathrm{~m} / \mathrm{s}$, the technical action keep in line with the principle of whipping.

\subsection{Analysis of the follow through stage}

"Follow-through" means follow the previous action, make sure you finish all the movements and take the racket through the body to the sideways. The followthrough stage refers to the process from the moment of contact the ball to the end of the follow-through action. This action is also one of the essential stage in the forehand. The associated kinematic parameters of this

stage are signs of the momentum transmission when swing the racket to contact the ball. In the followthrough stage, Karen Khachanov used to the "screenwiper" mode, that is, from the moment of the ball be contacted, quickly rotated his forearm in the direction of left sideway, with the purpose to increase the speed of the racket head in the frontal plane, and made the ball had strong topspin.

Table 5. Parameters about the end of the follow-through

\begin{tabular}{|c|c|c|c|c|c|c|c|c|c|}
\hline \multirow{2}{*}{$\begin{array}{c}\text { Center of } \\
\text { gravity } \\
\text { (m) }\end{array}$} & \multirow{2}{*}{$\begin{array}{c}\text { Right } \\
\text { shoulder } \\
\left({ }^{\circ}\right)\end{array}$} & \multirow{2}{*}{$\begin{array}{l}\text { Right } \\
\text { elbow } \\
\left({ }^{\circ}\right)\end{array}$} & \multirow{2}{*}{$\begin{array}{c}\text { Shoulders } \\
\text {-hips } \\
\left({ }^{\circ}\right)\end{array}$} & \multicolumn{2}{|c|}{ Hips $\left(^{\circ}\right)$} & \multicolumn{2}{|c|}{ Knees $\left({ }^{\circ}\right)$} & \multicolumn{2}{|c|}{ Ankles $\left(^{\circ}\right)$} \\
\hline & & & & Left & Righ & Left & Right & Left & Right \\
\hline 0.97 & 84.5 & 106.8 & 76.3 & 167.7 & 177.2 & 139.2 & 115.0 & 113.5 & 119.5 \\
\hline
\end{tabular}

At the end of the follow through action, Karen Khachanov's right shoulder, right elbow angle were 84.5 ${ }^{\circ}, 106.8^{\circ}$, which means his shoulder and elbow were bent naturally. Shoulder-hip angle was $76.3^{\circ}$, indicated that Karen Khachanov made full use of the rotational inertia that generated by twisted his torso, send the shoulder action obviously, and increased the role of this racket on the ball time, and then increased the power of distance. The left and right knee angles were $139.2^{\circ}$ and $115.0^{\circ}$, the left and right ankle angles were $113.5^{\circ}$ and $119.5^{\circ}$, and the center of gravity was $0.97 \mathrm{~m}$. By observing the original video, with the end of the follow through action, Karen Khachanov's lower limbs have completed the buffer action, then enter the next stroke to prepare the action.

\footnotetext{
* Corresponding author: 549828421@qqq.com
} 


\section{Conclusions}

According to kinematical analysis on the forehand stroke of Karen Khachanov and draw the following conclusions:

\subsection{The backswing stage}

At the end of the preparation, Karen Khachanov's hips, knees, ankles joints were bent and bent similar size, body control was more stable; compared to the height of normal anatomical body, his center of gravity height was lowered $0.28 \mathrm{~m}$, body center of gravity kept a low position, ready for the back position.

At the end of the backswing stage, Karen Khachanov's right shoulder, right elbow joint angle were $79.4^{\circ}, 149.5^{\circ}$, racket-forearm angle was $136.8^{\circ}$, that means the articulation of the joint arm was more fully and the waving radius was larger; From his hips, knees, ankles angle can be seen, Karen Khachanov's right lower limb flexion was more obviously, the right leg from the main support role for the next stage of the leg to establish the basis for rotated his hips.

\subsection{The swing stage}

\section{References}

1. Tao Yang, Jihe Zhou. Kinematical analysis on the forehand stroke of Andy Murray [J].Sports vision, 2015, 34 (5) : 247-249.

2. Huifang Wang. Kinematical analysis on the forehand topspin stroke of ATP tennis players in chengdu[D]. Chengdu sport institute,2014.

3. Shengying Zhang, Wei Xu. Analysis on the technical characteristics of the World 's elite tennis players[J]. Sports Science and Technology in Hubei Province, 2010,1, (29) : 73-74.
At the moment of contact the ball, Karen Khachanov's center of gravity height was $0.94 \mathrm{~m}$, the right shoulder joint, right elbow joint and the knee arm angle were 62.3 $\circ, 107.1^{\circ}$ and $105.4^{\circ}$, respectively. through the data with the video recording, we can see that during the stroke process, Karen Khachanov controlled the starting point was more appropriate ; he rotated his hips adequately; the right shoulder, the right elbow, the right wrist joint and the head speed respectively, $2.68 \mathrm{~m} / \mathrm{s}, 5.46 \mathrm{~m} / \mathrm{s}$, $11.21 \mathrm{~m} / \mathrm{s}$ and $22.61 \mathrm{~m} / \mathrm{s}$, the proximal end to the distal end of the speed increases, in line with the principle of whipping.

\subsection{The follow-through stage}

At the end of the follow-through, Karen Khachanov's lower limb joints were still bent, the center of gravity height was $0.97 \mathrm{~m}$, the body control is smooth; the shoulder hip angle was $76.3^{\circ}$, making full use of the torso twist generated by the moment of inertia. Sending the shoulder action is obviously, at the same time, it increased the role of this stage racket on the ball time, and then increased the work distance, the action is fast and powerful.
4. Ting Jiang, Bing Qi. Kinematic research on the forehand Stroke of different horizontal tennis players[J]. Journal of Beijing Sport University, 2014,9 (37) : 128-132.

5. Hang Li. Kinematical analysis on the difference forehand stroke style: flat and topspin[D].Shenyang sport institute, 2012.

6. Jian Guo. Biomechanical analysis and evaluation of tennis forehand stroke technique[J]. Athletics Forum,2009,12 (17) :53-55.

\footnotetext{
* Corresponding author: 549828421@qq.com
} 